\title{
Land reclamation and water management in an arid region: a case study of Xayar county in Xinjiang Uygur autonomous region, China
}

\author{
T. Yamamoto ${ }^{1}$, A. Jalaldin ${ }^{2}$, A. Maimaidi ${ }^{3}$ \& T. Nagasawa ${ }^{1}$ \\ ${ }^{1}$ Research Faculty of Agriculture, Hokkaido University, Japan \\ ${ }^{2}$ College of Resources and Environmental Sciences, \\ Xinjiang University, China \\ ${ }^{3}$ Xayar Water Resource Agency, China
}

\begin{abstract}
Irrigation is indispensable in guaranteeing agricultural production in arid regions, such as the Tarim Basin. In this region, administrations and farmers have reclaimed wild land, and have attempted agricultural development by securing the water resources. However, this area faces problems with an extremely irrational plan between land reclamation and water resource development, which has resulted in an acute shortage of water in this region. The situation has also caused ecological damage. This paper discusses this region's problems with agricultural water use and farmer's activities. It is shown that water supply volume per unit of farmland is tending to decrease. It is also clear that the water supply from the river has decreased greatly in the region where water-saving irrigation by groundwater pumping was introduced earlier. Water-saving irrigation is being introduced to resolve the water shortage and create new water resources. Although it seems to be effective for saving water resources, improper management hinders effective irrigation in this region. In particular, considering that water management is different among landowners and farmers, it has become clear that there are several problems - lack of an adequate management system and training system for facilities maintenance, etc. - that need to be resolved for water-saving irrigation in the region.
\end{abstract}

Keywords: Tarim River, water-saving irrigation, land and water management. 


\section{Introduction}

In arid regions, agriculture and human activities are possible only where there is a source of water. Desert oases exist because of the water resources located there. The Taklamakan Desert is located in Central Asia, in the Xinjiang Uyghur Autonomous Region of the People's Republic of China. It is bounded by the Kunlun Mountains to the south, and the Pamir Mountains and Tian Shan to the west and north. A large area of farmland exists in the border area of the Taklamakan Desert, an achievement that was made possible through the development of water resources and the construction of irrigation facilities. Expansion of food demand and industrial output through population increases in China are major factors in the development of agriculture in such regions where water resources are inadequate. Development of farmland and water resources has been facilitated through an injection of both capital and technology involving (1) the Xinjiang Production and Construction Corps (a unique economic and semi-military governmental organization existing in the Xinjiang Uyghur Autonomous Region) and (2) the Great Western Development Strategy, a governmental policy aimed at opening up less developed regions of China. These projects are geared toward agricultural promotion through the reclamation of farmland from deserts and the development of water resources. However, water shortages have occurred because of irrational planning of land reclamation and water resource development [1]. In addition to water shortages for agricultural production, the regional and river basin ecosystem has become degraded due to human activity [2]. In attempting to combat water shortages in this region, the effective use of groundwater, which exists in large amounts, and the reduction in water loss through lining the canals are both effective measures [3]. On the other hand, because groundwater levels depend on the extent of seepage of irrigation water [4], the groundwater resources decrease if seepage is prevented. Moreover, exhaustion of groundwater resources by widespread pumping has been recorded by Xinan Deng et al. [5] and others. To summarize, sustainable and effective utilization of groundwater is not a simple matter.

In this study, problems relating to agricultural water use are discussed against a background of actual conditions of water resources and agricultural activities under irrigation, especially water-saving irrigation, in Xayar County, Tarim River basin. Future water management and effective water resources are also examined.

\section{Methods and outline of investigation area}

The investigation targeted Xayar County, which is located in the Taklimakan Desert in the northern border region of Xinjiang Uyghur Autonomous Region. Xayar County is within the Aksu Prefecture and is located in downstream of the Ugen River, which is a branch of the Tarim River (Fig.1). The county population is 174,000 and its area is $31.9 \times 10^{2} \mathrm{~km}^{2}$. The main local crop is cotton, and irrigation water relies on the Kyzyl Dam upstream of the Ugen River. Many 


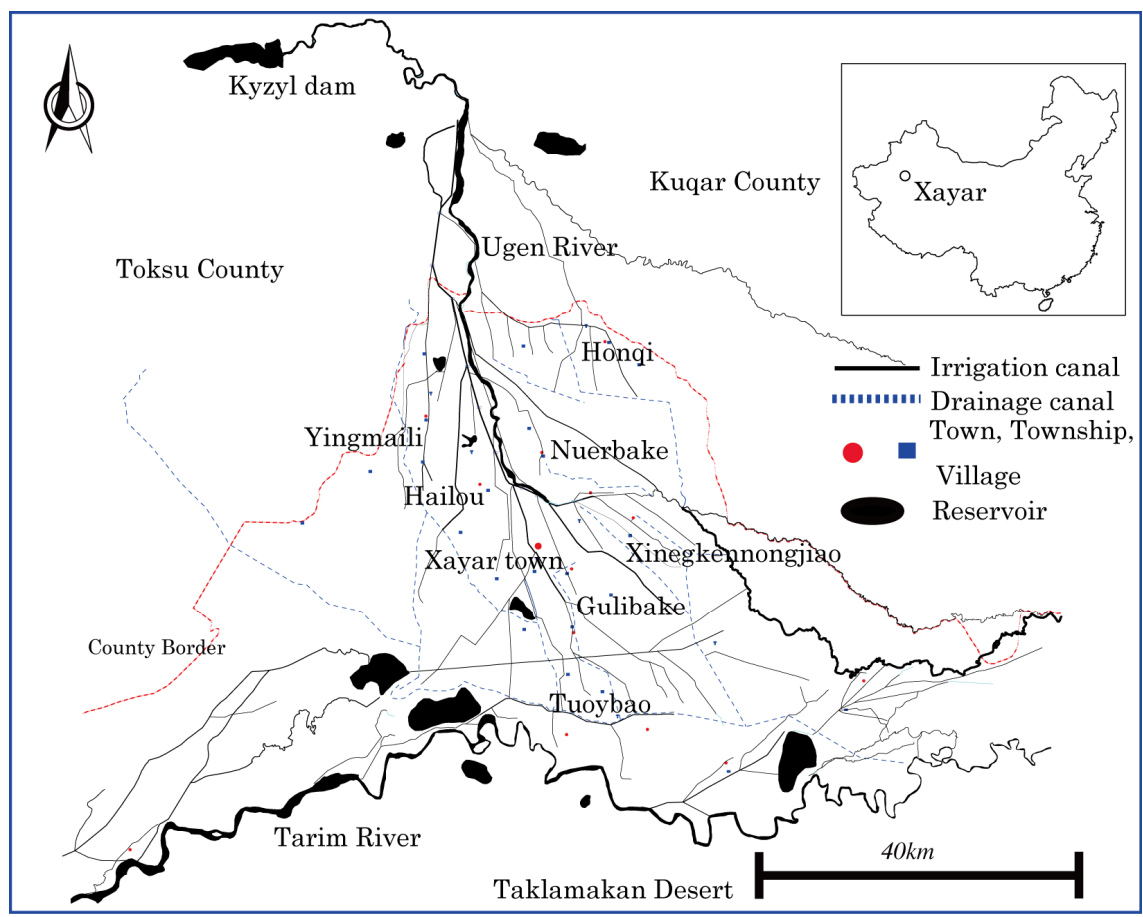

Figure 1: Investigation area.

irrigation resources in the Ugen River basin are derived from a mountain glacier. The Kyzyl Dam supplies water to three counties: Xayar, Kuqar, and Toksu. The administrative and irrigation districts are numerous. The Xayar County administration is divided into eight "townships and towns" (from upriver down; Honqi, Yingmaili, Nuerbake, Hailou, Xayar Town, Xinkennongjiao, Gulibake, and Tuoybao) in the Xayar irrigation district. Irrigation water from the Ugen River is supplied to these townships and towns. However, part of the intake is from the Tarim River in Tuoybao Township, and there are several family-run farms in this district. On the other hand, in Xinkennongjiao, the farmland has been developed through national enterprise, with many landowners and a few family-run farms.

To ascertain the prevailing state of irrigated agricultural enterprise, interviews with representatives of branch offices of the local water resource agency and some farmers were conducted from 2003 to 2009. In the interviews, we mainly researched the irrigation method, irrigation frequency, problems in irrigation, facilities management, farmers' income, and family structure, etc. Data concerning the irrigation water supply from 1998 to 2008 and for farmland areas in townships in Xayar County in 2007 were obtained from this agency. The water supply data is the daily volume of irrigation water distributed from the main irrigation canal to each township and town. 


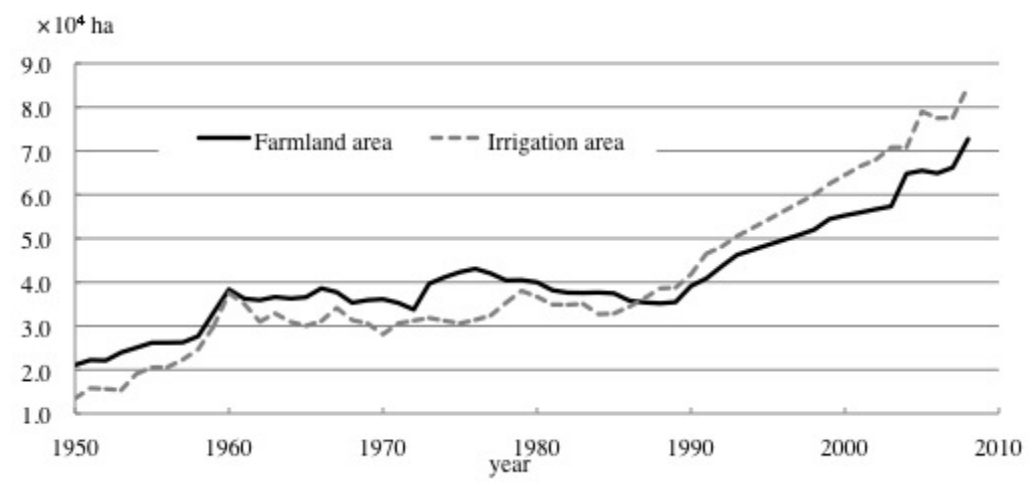

Figure 2: Changes in cultivated and irrigation areas in Xayar County. This figure was created by modifying data from Jalaldin et al. [1].

\section{Farmland development and land-use rights}

\subsection{Changes in farmland and irrigation areas}

Figure 2 shows changes in the farmland and irrigation areas of Xayar County since 1950. Since that year, farmland areas have greatly increased under China's Great Leap Forward policy, but the expansion rate eventually slowed. An increase was again seen, fuelled first by the inflow of capital and technology under the Economic Reform policy of the 1990s and then through the Great Western Development Strategy starting in 2000. The current agricultural area is now three times greater than that in 1950 (i.e., 60,000 ha). Although the irrigated area was smaller than the farmed area until 1987, the former is now increasing each year at a greater pace than the latter. The main factors leading to the increase in irrigation are the advances made in irrigation systems through the investment of capital and technology and the consequent potential for double cropping. The Kyzyl Dam, which was completed in 1991, has facilitated a far greater reliability of irrigated water supply, circumventing the need to obtain water from the Ugen River.

\subsection{Family-run and landowner farmers}

Farm ownership affects every agricultural activity (Fig.3). From results of the interview research, we considered the effects of farm ownership. In China, ownership of all farmlands belongs to the nation. This began during the People's Commune period. After the Economic Reform Policy, only the 30-year's landuse rights were given for the purpose of expanding farmers' independent management to increase food production. In other words, the current farmers borrow land-use rights through contracts with the nation. First, farmland (i.e., 30 year's contract farmland) is distributed equally among farmers in a village, and 


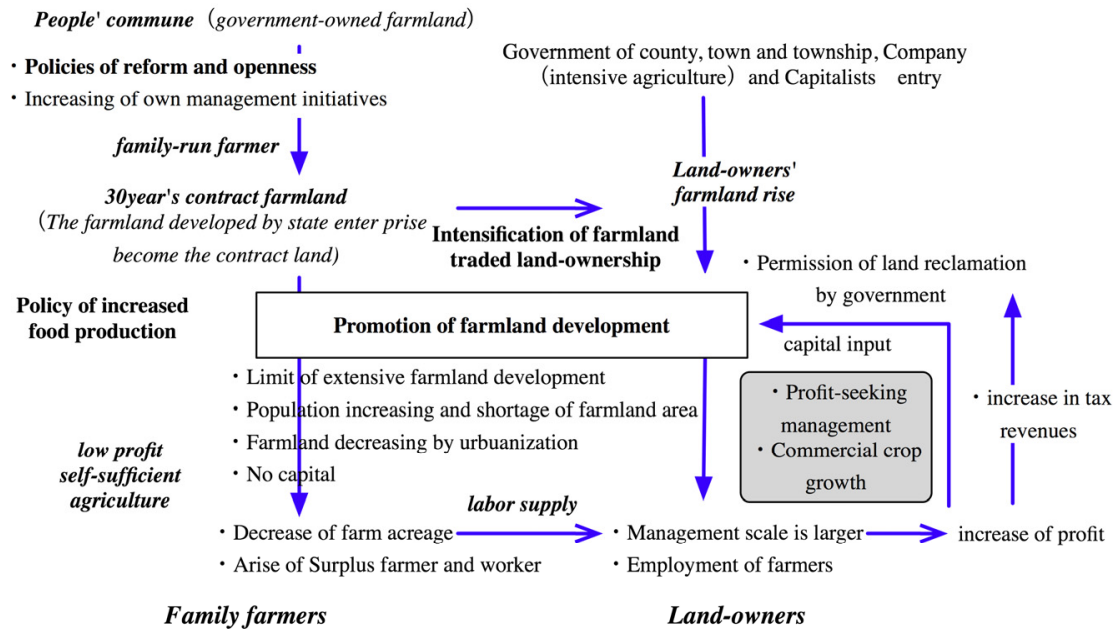

Figure 3: Concept of ownership of the land-use rights.

each farmer owns land-use rights. But the land-use rights in newly developed farmlands are sold because specific farmers cannot own these rights, and the original farmers do not stay on the farms. At this time, people have become landowners because of taking land-use rights through administrative organizations, companies, and capitalists. Many landowners pushed forward scale expansion of the management to buy not only the rights of developed farmland but also general farmers' farmland. Farmland developed by not only state enterprise but also each level of administration organization or individuals (rich farmers, companies, capitalists) under the food production increase policy. It was difficult to expand the farmland area in some old village that has little development appropriate place. In addition, when the population increased, the management scale per a farmer decreased because the farmland need to be divided into new family and farmers are limited to leave from the village in China. So the original farmers seemed hardly to management with advantage of scale. As a result, small-sized agricultural management on self-support crops was mainly in many farmers. However, the farmers who owned the farmland under optimum production conditions or who have the opportunity for scale expansion can get some profit to cultivate commercial crops (cotton and fruits) with selfsupporting crops. The landowner farmers have enabled the large-scale management of commercial crops to use the surplus labour of those that have too little farmland to be self-sufficient or have no land-use rights. In addition, they have further expanded and construct the new irrigation facilities. Although new land reclamation is currently subjected to rigid control, the permission of land reclamation for landowners tends to be accepted easily because of the increase in tax income incurred. 


\section{Water management and changes in supplied water}

\subsection{Irrigation methods and maintenance rules}

Many irrigation resources in the Tarim River basin are derived from a mountain glacier, therefore, the volume of irrigation water increases in the summer but decreases in the winter. Although the Kyzyl Dam constitutes the main water resource in this region, there is a very distinct seasonal bias, with inflow and outflow for irrigation being concentrated in the summer months [6].

The irrigation water is supplied by the Longkou diversion headworks to the Xayar Main Irrigation Canal (length, $50 \mathrm{~km}$ ). The water is delivered using a fivestep canal irrigation system [6]. In this county, the lining rate over the total canal length is only $4 \%$, conveyance efficiency is about $60 \%$, and irrigation efficiency is only $40 \%$. Irrigation is performed mainly from the spring through the summer, and minimal in winter. From the spring through the summer, irrigation water is used for general crop growth. Winter irrigation aims at maintaining soil moisture, which would otherwise be low in the early spring sowing period. Border and furrow irrigation occupy about $80 \%$ of farmland in Xinjiang [7], and it is similar condition in this region. In addition, water-saving irrigation technology has been introduced in recent years.

The water resource agency in this county is responsible for maintenance of the main canal and water distribution to each township or town, and each branch office is responsible for the management of water distribution and maintenance within each settlement. Water supply to each farm is overseen by local office staff and farmers' representatives. When the irrigation water supply is adequate, the appropriate level of water is distributed for each crop and planted area. However, during shortages, irrigation for all the fields is not possible. Therefore, the following rules exist when establishing priority [8].

Spring-summer:

- Upriver takes priority over downriver.

- Larger canals (or irrigation blocks) take priority over smaller canals.

Winter:

- Downriver takes priority over upriver, because water shortages are more likely downstream at sowing time.

- Wheat fields and land under 30 years' contract take priority.

\subsection{Monthly irrigation water volume}

Figure 4 shows the variations in the monthly supply of water per unit area to each town and township from 1998 to 2008 . The irrigation area values in each town or township were not obtained except in 2004 and 2007, and these values are presumed from two years of data. The largest volume is supplied in July, followed by August, partly because of high summer temperatures. March and November also show peaks: the former being when sowing occurs and the latter when irrigation is required for wheat. Although irrigation is also required in December and February, this is winter irrigation, as explained above. 


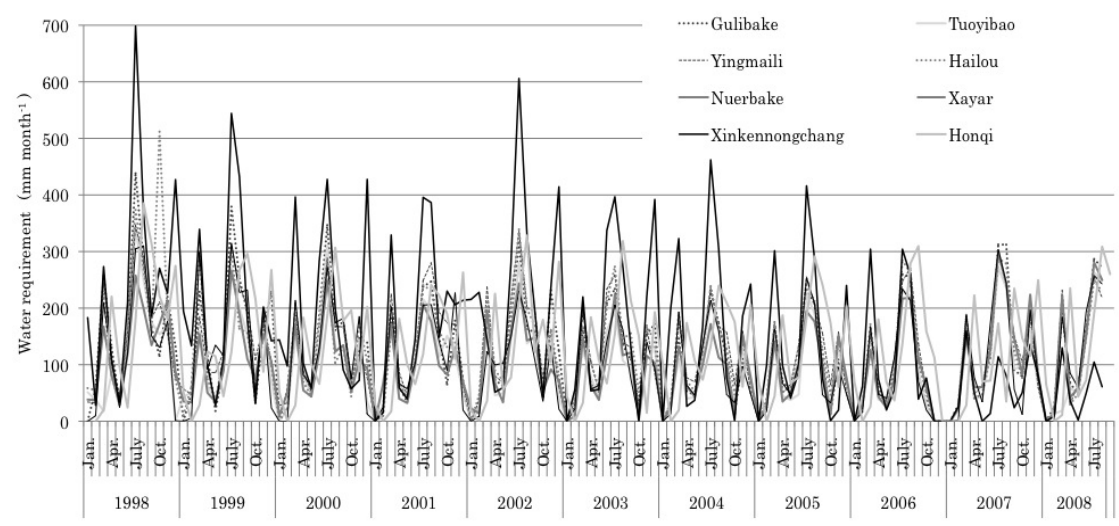

Figure 4: $\quad$ The irrigation water supplied in each township and town.

The water supply is found to decrease in each town or township. The decrease was small for all towns and townships except for Xinkennongjiao Township. This reduction in irrigated water supplied is remarkable in Xinkennongjiao Township. One of the reasons for such a decrease may be the abandonment of farmland. However, we cannot detect any reason that farmland decreased. Therefore, the reduction in irrigation water supplied is considered to be attributable to other factors. Maintenance levels of the irrigation canal have not achieved a higher rate of conveyance efficiency in this particular township nor has there been any major shift in the types of crops grown locally. It is therefore believed that irrigation water must be supplied from other resources, and it is surmised that an increase in groundwater is the reason. According to the authorities, since 2004 a large area in Xinkennongjiao Township has been able to reduce requirements for irrigated water by using groundwater. Why has this not occurred in any other township? The main reasons are that the economic burden involved in construction of facilities is large, and there is inadequate technical input for water-saving irrigation.

\subsection{Water fees and water-saving consciousness}

We considered the influence on water-saving consciousness by water fees from results of interview to Water Resources Agency and its brunch offices. Before 2000 , the water fee per unit area of crops was fixed, and farmers paid taxes according to their own farmland areas. Therefore, because the payments did not change no matter how much irrigation water farmers used, farmers were not motivated to save water. In addition, many complaints occurred in the downstream farmland located far away from the water resource, because enough irrigation water did not reach to waste in the upper farmlands. The government decided that new water price rules should depended on the irrigation water volume in a wider area of this Autonomous Region after 2000. As a result, although wasting of irrigation water and feelings that water fees are unfair have 
declined, the water shortage has not yet completely resolved. In addition, the uniform maintenance level of irrigation facilities is demanded to apply new water price rule. However, actually, there is also an area where the maintenance level is insufficient (lining rate is too small), and the introduction of the new rule is difficult. So it is in situation that an old rule and a new rule are being used appropriately according to the maintenance level of the irrigation facilities. In many farmlands, the cost of water is collected under such a rule. On the other hand, when water-saving irrigation facilities are improved individually (in many cases the irrigation water depends on groundwater), it doesn't require the water fee of groundwater basically. Therefore, the incentive for saving water costs occurs through advancing water-saving irrigation. But because electricity costs are needed for pumping up groundwater, many farmers believe that the cost of electricity is higher than the cost of water or the facilities cost is higher.

\section{Problems with introducing water-saving irrigation}

\subsection{Introduction of water-saving irrigation}

Chronic water shortages are a problem in this region, and the introduction of water-saving irrigation has been proposed as a solution. The following matters were found in the interview researches. Since 2007 a water-saving project has been in place for farmers in Xayar County. Water-saving irrigation facilities (i.e., drip irrigation) have been improved for about 10,000 ha (150,000 mu in Chinese units) of farmland, equal to about $10 \%$ of the total cultivated area in the county. The Chinese government subsidized one-third of the total cost of construction. The remaining cost is borne by the county and farmers. Farmers paid roughly $800 \mathrm{CNY}$ per 0.067 ha (about $1 \mathrm{mu}$ ). However, irrigation facilities cannot necessarily be constructed on any farmland. Local construction standards recommend one pumping facility for irrigation of about 27 ha (400 mu). Construction of this facility is difficult for the common family farmer because each farmer in this region manages about 1.3 to 2.0 ha $(20-30 \mathrm{mu})$. Although this is about 6.7 ha in Tarim Township, the construction of a pumping facility is not cost-efficient for the one family farmer and it is never a cheap investment, considering that their profit from production is about 1,200 to 2,000 CNY per year. On the other hand, some farmers indicated that the irrigation volume by river intake decreased to one-third of that before using water-saving irrigation. Some farmers in Xinkennongjiao Township and the water resource agency branch office staff in Tarim Township stated that cotton production increased as result of water-saving irrigation.

\subsection{Problems with management of water-saving irrigation facilities}

Limiting construction of these facilities by farmland scale does not arise for the landowners because their land holdings are large enough to justify the construction of facilities on their land. The landowners (or the responsible farmers employed) manage these facilities by themselves. On the other hand, in 
the case of the common farmers, their representatives control each pump. In addition, even if irrigation priorities are decided, some farmers cannot understand correct operation of the facilities provided, or there may be a lack of cooperation with other farmers. Therefore, each farmer irrigates independently; as a result, the water pressure in some irrigation pipes decreases, causing shortages of irrigation water. Naturally, the management of a pump is unified, and the rotation rule of which farmland irrigate is not also defined correctly. On occasions, disruption in the water supply occurs because the pipes upriver are cut to monopolize supplies. In the case of some common farmers in Honqi Township, the water-saving irrigation was costlier than irrigation from river intake because water-saving irrigation could not be managed effectively. Problems are exacerbated because farmers are only given a manual to learn about the scheme, and the manual is in Chinese, which may not be their spoken language. The water resource agency can't respond to this problem because of its insufficient budget.

\section{Assignment for sustainable irrigation}

\subsection{A cause of water shortage}

Irrigation water demands (design net water requirement) and requirements in Xayar County are shown in Figure 5 representing design net water requirements, water requirements (supplied irrigation water), and presumed net water requirements (water requirement $\times 0.4$ : irrigation efficiency in this region [1]), respectively. The total design net water requirement is calculated from the cultivated area according to crops grown in the years 2004 and 2008 and to the design net water requirement for each crop. Data for each cultivated area from 2005 to 2007 that were not available were calculated from the transition in cultivated field area over the same period. C is less than A between 2004 and 2008 , and the average annual shortfall volume is $7.6 \times 10^{7} \mathrm{~m}^{3}$. It is thought that there is sufficient water requirement (B), although many farmers argue strongly that there is a shortage of water.

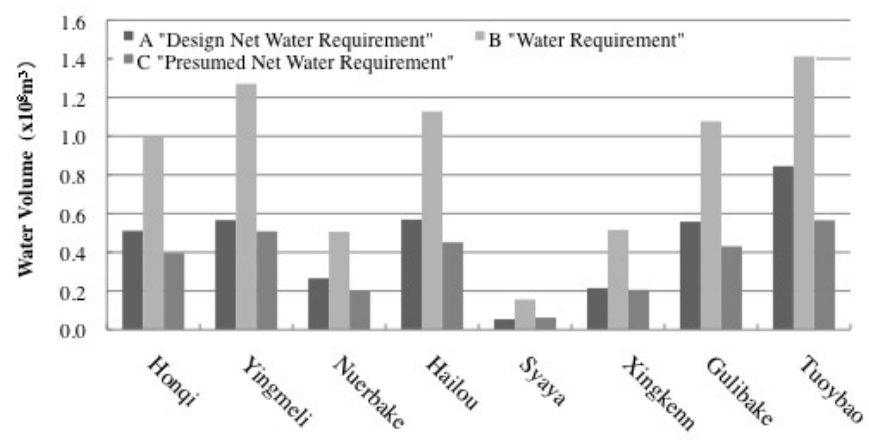

Figure 5: $\quad$ Irrigation water demands and requirements. 


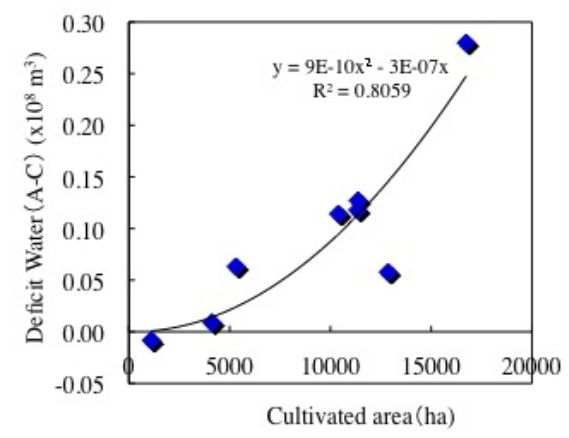

Figure 6: Relationship between deficit water and cultivated area.

The relationship between water volume deficit $(\mathrm{B}-\mathrm{C})$ and the cultivated field area shows that the former becomes larger by expansion of the cultivated area (Fig. 6). Because expansion of the cultivated area indirectly indicates the total length of the main channel, it is suggested that a water shortage has occurred because of seepage from both canal and irrigation channels.

\subsection{Relationship of land reclamation to water resource development}

We think that an irrational relationship between farmland and water resources developments is one of the factors causing water shortage in this region. In Japan, farmland reclamation and water resources development are usually planned integrally. Developed farmland area limits the necessary water resource scale, or an irrigation area is decided with the amount of water resources that it can supply. However, in this region, the section that permits the farmland reclamation and the section that take charge of water resource development and management were separate. As result, the adjustment in the development plan (also after development) is insufficient, making water supply and demand unbalanced.

The section that permits farmland development is different from a prefecture, a county, and a township, depending on the size of reclamation area, and the influence of the water management section (i.e., water resource agency) on this permission is barely reflected. But the section that manages and supplies water is responsible for distributing irrigation water equally to the existing farmland. Therefore, a shortage of water develops naturally if farmland extends without water resources developing. At this time, there is administrative instruction by the Autonomous Region or Prefecture governments; however, the effect is weak because there are uncertainties and insufficient statistics data to understand irrigation area [2]. It is also considered the section that permits farmland development judged there was enough area of possible reclamation area, because they didn't understand certain data. As result, they permitted the new farmland development over the limit of water supplied. Such a vicious circle has aggravated the water shortage. 


\subsection{Requirements of effective utilization of water resources}

It was indicated that the water shortage has occurred in each field due to water seeping through the canal; however, the volume of irrigation water supplied was sufficiently in Xayar County (Fig. 5). This problem may be solved by improving the efficiency of the water supply by lining the canal. However, the cost of lining the entire canal is immeasurable. In addition, it can be predicted that it will be necessary for long-term for restoration of canals' freeze-fracturing. Therefore, to secure irrigation water in a short time period, the introduction of saving-water facilities is regarded as an effective method and the administrative organization does not need to manage and construct for individual facilities. Some farmers said in their interviews that the saving-water facilities are effective in conserving water resources and increasing production. Such an effect is confirmed under the appropriate management, and the general farmers have a problem on the management. It is necessary to support these farmers to achieve the certain effects of water-saving irrigation. For this purpose, important factors are (1) financial support more than current, (2) the establishment of a training system for facilities maintenance, and (3) substantially raising the farmers' water-saving consciousness.

\section{Conclusion}

This study has shown that water-saving irrigation is effective in saving the water resources from the daily supplied water data and the interview researches. However, the introduction of water-saving irrigation is not necessarily effective in all cases. It is evident that the effects of water-saving irrigation are different for the landowners versus common farmer, even if facilities are similarly constructed. The differences in land-use rights and the amount of capital are large problems in the introduction of water-saving irrigation.

It was also confirmed that the main cause of water shortage is seepage from branch canals before reaching farmlands; the volume of supplied water is not the problem.

The development of water-saving irrigation will be indispensable to the preservation of water resources in this region in the future. The influence of pumping of groundwater on natural vegetation is of concern, and the environmental impact of this on large areas has not yet been realized. It will be necessary to examine these environmental concerns, including evaluating groundwater resources.

\section{Acknowledgements}

Research was supported by Xayar County Government, Xayar Water Resource Agency, Xinjiang University and Xinjiang Uyghur Autonomous Region Water Resource Agency. 
14 Sustainable Irrigation Management, Technologies and Policies III

\section{References}

[1] Abdisalam Jalaldin, Nagasawa Tetuaki \& Yamamo Tadao (2005). Irrigated agriculture and regional environment in the Tarim River watershed - case study of the shaya irrigated district in the Ugen River basin -. Journal of Rural Planning 7, 73-78.

[2] Q. Feng, K.N. Endo \& G.D. Cheng (2004). Towards sustainable development of environmentally degraded arid rivers of China - a case study from Tarim River -. Environmental Geology 41, 229-238.

[3] Fan Zili, Xia Xuncheng, Shen Yuling, Alishir Kurban, Wang Ranghui, Li Shemgyu \& Ma Yingjun (2002). Utilization of water resource, ecological balance \& land desertification in the Tarim Basin, Xinjiang. Science in China, 45, 102-108.

[4] Ma Jin-zhu, Li Ji-jun (2001). The groundwater resources and its sustainable development in the south edge of Tarim Basin. Chinese Geographical Science 11(1), 57-62.

[5] Xinan Deng, Yuzhou Luo, Sucheng Dong \& Xiusheng Yang (2005). Impact of resources and technology on farm production in northern China. Agricultural Systems 84, 155-169.

[6] T. Yamamoto, T. Nagasawa \& A. Jalaldin (2006). Irrigated agriculture and the environment in the Tarim River watershed: case study of the shaya irrigation district in the Ugen River basin. Sustainable Irrigation Management, Technologies and Policies, WIT Press, 303-312.

[7] Zhong Ruisen, Dong Xingyang \& Ma Yingjie (2009). Sustainable water saving: New concept of modern agricultural water saving, starting from development of Xinjiang's agricultural irrigation over the last 50 years. Irrigation and Drainage 58,383-392.

[8] Yamamoto Tadao, Abdisalam Jalaldin, Anwaire Maimaidi \& Nagasawa Tetuaki (2010). The present condition and problem of agricultural water management in northern part of Taklamakan Desert. $1^{\text {st }}$ International Conference on Environmental and Rural Development (in press). 